\title{
Bean seed maggot (Hylemyia florilega Zett.) a threat to green bean production in Masovian voivodeship
}

\section{Zagrożenie uprawy fasoli szparagowej przez śmietkę kiełkówkę (Hylemyia florilega Zett.) w województwie mazowieckim}

\author{
Piotr Kozłowski*, Anna Tomczyk
}

\section{Summary}

Two-year observations were carried out on the occurrence and damages caused by bean seed maggot (Hylemyia florilega Zett.) in the area of extensive cultivation of green beans, in Masovian region. The pest was monitored by using yellow sticky traps at the time of seed sowing in May 2013 and 2014. Population of flies on experimental plots was high in both seasons and maximum of their occurrence was observed in the first half of May. In 2013 ten percent plants showed damages while in 2014 twenty percent of plants were destroyed and, majority of them at the early stage of development. High percentage of damages resulted from intensive cultivation of green beans in both experimental years in this region.

Key words: Hylemyia florilega; green bean; monitoring; seed damages

\section{Streszczenie}

Przeprowadzono dwuletnie obserwacje występowania i szkodliwości śmietki kiełkówki (Hylemyia florilega Zett.) w rejonie uprawy fasoli szparagowej w województwie mazowieckim. Szkodnika monitorowano za pomocą żółtych tablic lepowych w maju 2013 i 2014 roku od momentu wysiania nasion. Liczebność szkodnika była wysoka w obydwu sezonach, maksima pojawu obserwowano w pierwszej połowie maja. W roku 2013 stwierdzono 10\% uszkodzeń roślin, a w roku 2014 ponad 20\% roślin uległo zniszczeniu, większość w najwcześniejszym stadium rozwoju. Uprawa fasoli na tym samym stanowisku w drugim roku doświadczenia powodowała większą liczbę uszkodzonych roślin.

Słowa kluczowe: Hylemyia florilega; fasola szparagowa; monitoring; uszkodzenia nasion

\author{
Szkoła Główna Gospodarstwa Wiejskiego w Warszawie \\ Samodzielny Zakład Entomologii Stosowanej \\ Nowoursynowska 159, 02-776 Warszawa \\ *corresponding author: piotr_kozlowski1@sggw.pl
}




\section{Wstęp / Introduction}

Śmietka kiełkówka (Hylemyia florilega Zett.) to przykład typowego polifaga, szczególnie chętnie atakującego rośliny dyniowate, bobowate oraz szpinak (Jaramillo i Sáenz 2013). W sprzyjających dla niej warunkach może rozwijać się w rejonach uprawy fasoli szparagowej. Duże liczebnie populacje mogą powodować silne uszkodzenia kiełkujących nasion i młodych roślin, co zwykle prowadzi do dużych strat w plonie. Larwy muchówki doprowadzają do zniszczenia kiełkujących nasion różnych gatunków roślin. Młode larwy początkowo żerują w resztkach roślin i oborniku, później wgryzają się do kiełkujących nasion. Miejscem wnikania larw jest część podliścieniowa kiełków. Po przedostaniu się do wnętrza młodych roślin, larwy silnie uszkadzają siewki i powodują ich obumieranie (Szafirowska i Kaniszewski 2014). Szkodliwość gatunku zwiększa się w miejscach osłoniętych przez zarośla i zadrzewienia.

Obecnie w Polsce nie ma żadnych dostępnych środków chemicznych zarejestrowanych do walki ze śmietką kiełkówką. Odmiany wcześniejsze fasoli szparagowej są częściej atakowane przez szkodliwe larwy. Według badań Szafirowskiej i Kłosowskiego (2011) najchętniej atakowaną odmianą fasoli jest Aurora. Aby ustrzec się strat powodowanych przez żerowanie larw wskazane jest wysiewanie nasion w późniejszym terminie, ponieważ larwy chętnie żerują w nasionach długo kiełkujących, przy niskiej temperaturze powietrza (Szafirowska i Kłosowski 2011).

Szczególnie ważnym elementem ochrony fasoli szparagowej przed żerowaniem larw śmietki kiełkówki jest monitoring występowania osobników dorosłych. Dzięki prowadzonym obserwacjom można oszacować szkodliwość i występowanie osobników dorosłych śmietki w uprawie (Walczak 2010). Do monitorowania obecności śmietki kiełkówki w uprawie warzyw wykorzystywane są żółte tablice lepowe umieszczane na statywach. Dzięki obserwacjom w danym sezonie wegetacyjnym można prognozować liczebność populacji szkodnika w kolejnym sezonie wegetacyjnym (Vernon i Broatch 1996).

Celem pracy było określenie dynamiki wiosennego pojawu śmietki kiełkówki w uprawie fasoli szparagowej odmiany Unidor i ocena uszkodzeń spowodowanych przez larwy śmietki.

\section{Materiały i metody / Materials and methods}

Przeprowadzono dwuletnie obserwacje nad występowaniem i szkodliwością śmietki kiełkówki w rejonie uprawy fasoli szparagowej, w województwie mazowieckim (miejscowość Młodzieszyn $20^{\circ} 12^{\prime} \mathrm{E} \quad 52^{\circ} 18^{\prime} \mathrm{N}$ ). Badania prowadzono na odmianie fasoli szparagowej Unidor. Założono 5 poletek o wymiarach $2 \times 2 \mathrm{~m}$. Poletka były oddzielone od siebie ścieżką szerokości około $0,5 \mathrm{~m}$. Na każdym poletku wysiano 200 nasion fasoli szparagowej w dniu 1 maja 2013 i 2014 roku. Każde poletko stanowiło oddzielne powtórzenie. Odmiana fasoli Unidor jest bardzo plenna, uprawiana na plantacjach wielkotowarowych i chętnie wykorzystywana do mrożenia. Uprawia się ją również na plantacjach małoobszarowych. Przeznaczona jest wówczas do sprzedaży na rynku hurtowym i detalicznym. Fasolę szparagową tej odmiany uprawia się coraz częściej $\mathrm{w}$ tunelu foliowym jako uprawę przyspieszoną. Fasola szparagowa odmiany Unidor charakteryzuje się wysmukłym kształtem roślin. Strąki tej odmiany są długie, błyszczące, proste i intensywnie żółte.

Śmietka kiełkówka była monitorowana za pomocą żółtych tablic lepowych. Określano liczbę dorosłych osobników odłowionych w maju, w obydwu latach badań. Pułapki zakładano równocześnie $\mathrm{z}$ wysiewaniem nasion fasoli do gruntu. Do sygnalizowania obecności występowania śmietki kiełkówki wykorzystane zostały żółte tablice lepowe firmy Medchem o wymiarach $10 \times 20 \mathrm{~cm}$, umieszczone na statywach $20 \mathrm{~cm}$ nad powierzchnią gleby, po jednej tablicy na poletko.

Prowadzono obserwacje każdego z tysiąca (200 na poletko) kiełkujących nasion i młodych roślin fasoli szparagowej pod kątem ich uszkodzeń spowodowanych przez śmietkę kiełkówkę. Za uszkodzenia wywołane żerowaniem szkodnika przyjmowano: nasiona które obumarły, uszkodzone kiełki oraz siewki pozbawione liścieni.

Statystyczne opracowanie wyników wykonano w programie Statgraphic. Wyniki przeprowadzonych badań analizowano statystycznie $\mathrm{z}$ wykorzystaniem jednoczynnikowej analizy wariancji, za pomoca testu Fishera dla $\mathrm{p}<0,05$.

\section{Wyniki i dyskusja / Results and discussion}

W obydwu sezonach stwierdzono obecność śmietki kiełkówki w uprawie fasoli szparagowej. Badania wykazały, że przez cały okres prowadzenia monitoringu w obydwu sezonach wegetacyjnych (2013 i 2014), liczba odławianych osobników dorosłych $H$. florilega była na wysokim poziomie. Już w momencie wysiewania nasion liczba muchówek śmietki kiełkówki na poletkach doświadczalnych była wysoka i wkrótce osiągała maksimum. Maksimum lotu muchówek obserwowano w pierwszej dekadzie maja. Następnie liczba odłowionych szkodników nieco malała (rys. 1, 2). W sezonie 2014 liczebność szkodnika była wyższa niż w 2013, co miało związek z uprawą fasoli na tym samym stanowisku w ciągu dwóch kolejnych lat. W szczytowym okresie nasilenia lotu, w sezonie 2013 (trzy pierwsze terminy obserwacji), dziennie odławiano średnio jedną muchówkę na jedną tablicę. W trakcie maksimum lotu, w sezonie 2014 (trzy pierwsze terminy obserwacji), liczba odłowionych osobników na jedną tablicę wynosiła średnio 1,5 osobnika dziennie. Warunki pogodowe sprzyjały lotom muchówek w obydwu latach doświadczeń. Średnia temperatura w ciągu dnia wynosiła około $18^{\circ} \mathrm{C}$. Nie wykazano różnic istotnych statystycznie w liczbie odławianych osobników dorosłych między rokiem 2013 a 2014, jedynie w przedostatnim terminie obserwacji w roku 2013 liczba odławianych muchówek śmietki kiełkówki była istotnie wyższa niż w roku 2014 (miało to związek z wystąpieniem opadów deszczu w 2014 roku podczas prowadzenia obserwacji) (rys. 3). 


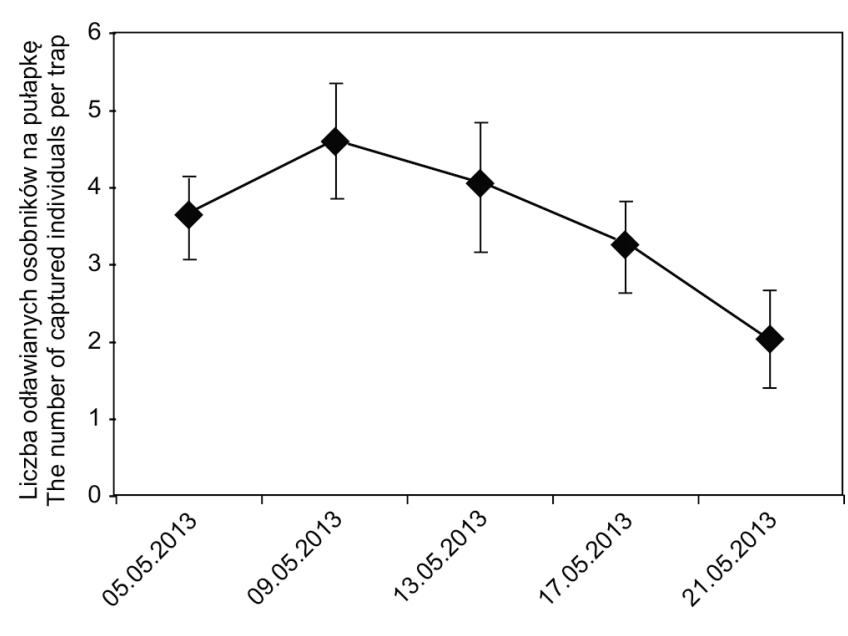

Data obserwacji - Observation date

Przedstawiono wartości SE (kolejne terminy obserwacji) Presented SE values (successive dates of observations)

Rys. 1. Liczba muchówek odłowionych na żółtą tablicę lepową, sezon 2013

Fig. 1. The number of flies caught on yellow sticky traps in 2013 season

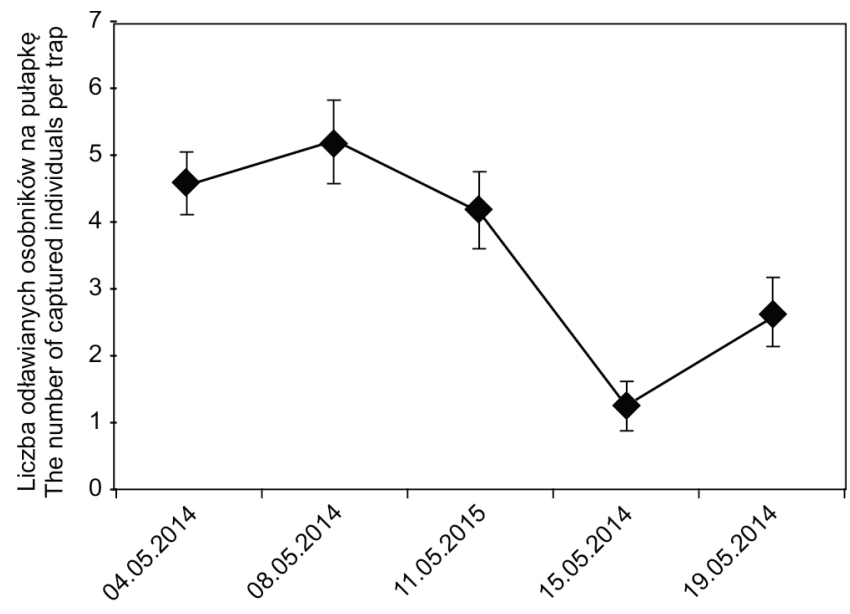

Data obserwacji - Observation date

Przedstawiono wartości SE (kolejne terminy obserwacji) Presented SE values (successive dates of observations)

Rys. 2. Liczba muchówek odłowionych na żółtą tablicę lepową, sezon 2014

Fig. 2. The number of flies caught on yellow sticky traps in 2014 season
Przy dużej liczbie odłowionych osobników dorosłych H. florilega można było spodziewać się licznego pokolenia szkodliwych larw śmietki kiełkówki oraz licznych uszkodzeń wschodzących siewek (Pustai i wsp. 2015), co zostało potwierdzone doświadczalnie (tab. 1). W obydwu sezonach stwierdzono znaczne uszkodzenia roślin. W badaniach wykazano, że w sezonie 2013 ponad 10\% siewek było uszkodzonych przez larwy śmietki kiełkówki, a w sezonie 2014 powyżej 20\% roślin uległo zniszczeniu (większość w najwcześniejszym stadium rozwoju) (tab. 1). Przyjęto, że 10\% uszkodzonych siewek fasoli przez larwy H. florilega będzie przekroczeniem progu ekonomicznej szkodliwości w następnym roku uprawy (Szwejda 2013).

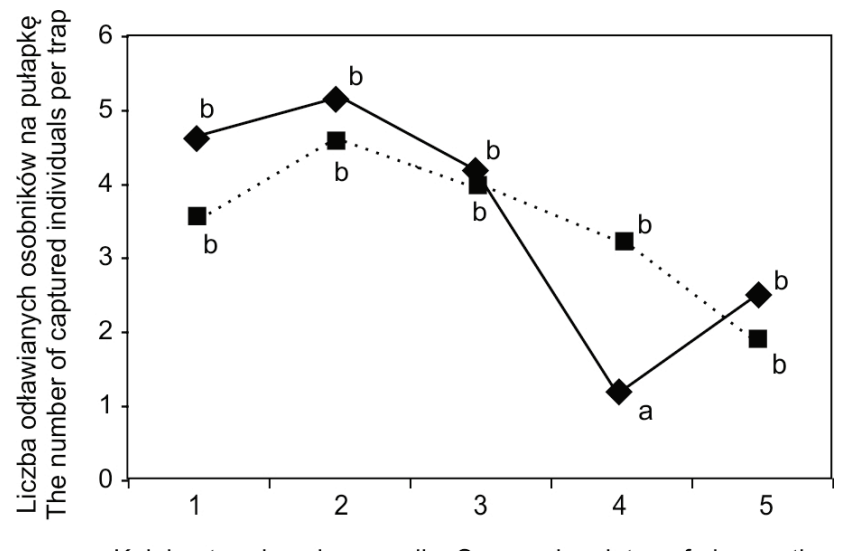

Kolejne terminy obserwacji - Successive dates of observation

$$
\begin{aligned}
& \text { Wiosenny pojaw Hylemyia florilega } 2014 \\
& \text { Spring occurrence of Hylemyia florilega } 2014 \\
& \text { Wiosenny pojaw Hylemyia florilega } 2013 \\
& \text { Spring occurrence of Hylemyia florilega } 2013
\end{aligned}
$$

Różne litery alfabetu oznaczają różnice istotne statystycznie w liczbie odławianych Hylemyia florilega w poszczególnych terminach obserwacji między sezonem 2013 i $2014\left(F_{1,9}=50 ; p=0,001\right)$ - Different letters of the alphabet indicate statistically significant differences in the number of trapped Hylemyia florilega in particular time of observation between 2013 and 2014 season $\left(F_{1,9}=50 ; p=0.001\right)$

Rys. 3. Porównanie nasilenia wiosennego pojawu Hylemyia florilega w sezonie 2013 i 2014

Fig. 3. Comparison of the severity of the spring occurrence of Hylemyia florilega in 2013 and 2014 season

Według doniesień naukowych wykazano, że larwy pierwszego pokolenia początkowo żerują W oborniku $\mathrm{i}$ resztkach roślinnych, następnie przedostają się do

Tabela 1. Uszkodzenia nasion fasoli szparagowej spowodowane żerowaniem Hylemyia florilegia w sezonach 2013 i 2014 (+/- SE) Table 1. Bean seed damage caused by feeding of Hylemyia florilega in 2013 and 2014 seasons (+/- SE)

\begin{tabular}{c|c|c|c}
\hline $\begin{array}{c}\text { Sezon } \\
\text { Season }\end{array}$ & $\begin{array}{c}\text { Liczba badanych nasion } \\
\text { The number } \\
\text { of examined seeds }\end{array}$ & $\begin{array}{c}\text { Średnia liczba nasion uszkodzonych } \\
+/- \text { SE } \\
\text { Average number } \\
\text { of damaged seeds }+/- \text { SE }\end{array}$ & $\begin{array}{c}\text { Procent uszkodzonych nasion } \\
\text { Percentage of damaged seeds }\end{array}$ \\
\hline 2013 & 1000 & $124+/-4$ & 12,4 \\
\hline 2014 & 1000 & $216+/-34 *$ & 21,6 \\
\hline
\end{tabular}

*różnice statystycznie istotne w liczbie uszkadzanych nasion przez larwy Hylemyia florilega między sezonami 2013 i 2014 - statistically significant differences in the number of damaged seeds by the larvae of s Hylemyia florilega seasons between 2013 and 2014 
kiełkujących nasion. Najczęściej owady wgryzają się w część podliścieniową kiełków. W trakcie żerowania, larwy mocno uszkadzają kiełkujące rośliny, powodują ich obumieranie, a następnie zamieranie (Finch 1989). Rozwojowi populacji owadów sprzyjają zadrzewienia i zakrzewienia sąsiadujące z polem uprawnym. Nawożenie obornikiem wiosną sprzyja migracji śmietki kiełkówki na plantację. Zabiegi agrotechniczne mogą przyczynić się do zmniejszenia liczebności populacji $H$. florilega w uprawie warzyw w polu. Wiosną pole powinno być starannie uprawione, bez grud ziemi i nierówności. Wszelkie wolne przestrzenie to doskonałe miejsca do złożenia jaj przez śmietkę kiełkówkę (Vernon i wsp. 2009).

Wcześniejsze odmiany fasoli szparagowej są częściej atakowane przez szkodliwe larwy śmietki kiełkówki. Aby ustrzec się przed żerowaniem larw śmietki należy opóźnić siew nasion. Larwy śmietki kiełkówki żerują przy niskich temperaturach gleby, gdy kiełkowanie nasion przebiega wolno. Wykazano, że opóźnienie siewu nasion fasoli o 10 dni powoduje zmniejszenie liczby uszkodzonych nasion o około 30\% (Szafirowska i Kłosowski 2011).
Obecnie w kraju nie ma żadnych dostępnych środków chemicznych zarejestrowanych do walki ze śmietką kiełkówką, dlatego należy wykorzystywać wszystkie dostępne metody przeznaczone do ograniczenia szkodliwości występowania $H$. florilega w uprawach polowych warzyw, w tym monitoring występowania osobników dorosłych, regulację terminów siewów oraz płodozmian.

\section{Wnioski / Conclusions}

1. Śmietka kiełkówka powodowała liczne uszkodzenia fasoli szparagowej we wczesnym stadium rozwojowym.

2. Uprawa fasoli szparagowej w dwóch kolejnych sezonach wegetacyjnych na tym samym stanowisku stymuluje pojaw śmietki kiełkówki i sprzyja uszkodzeniom przekraczającym próg ekonomicznej szkodliwości.

3. Zaleca się uprawę fasoli szparagowej w płodozmianie ze względu na wysoki stopień zagrożenia tej uprawy przez H. florilega.

\section{Literatura / References}

Jaramillo C.M., Sáenz A. 2013. Control of Delia platura (Diptera: Anthomyiidae) with Steinernema sp. strain JCL027 (Rhabditida: Steinernematidae) in commercial spinach. Nematropica 43 (1): 97-104.

Finch S. 1989. Ecological considerations in the management of Delia pest species in vegetable crops. Annual Review of Entomology 34: $117-137$.

Pustai P.M., Oltean I., Florian T., Bodis I. 2015. Monitoring of the crops pests of forage legumes in the area raciu, mureş. Bulletin of the University of Agricultural Sciences \& Veterinary Medicine Cluj-Napoca. Veterinary Medicine 72 (1): 202-208.

Szafirowska A., Kaniszewski S. 2014. Instrukcja uprawy fasoli zwykłej (Phaseolus vulgaris L.) na nasiona wwarunkach ekologicznych. Instytut Ogrodnictwa, Skierniewice. Pracownia Uprawy i Nawożenia Warzyw, 10 ss.

Szafirowska A., Kłosowski S. 2011. Evaluation of some dry bean cultivars suitability for organic cultivation. Journal of Research and Applications in Agricultural Engineering 56 (4): 134-137.

Szwejda J. 2013. Progi zagrożenia dla ważniejszych gatunków szkodników występujących na uprawach roślin warzywnych. s. 144-148. W: Program Ochrony Rośliny Warzywne. Hortpress, Warszawa, 302 ss.

Vernon R.S., Broatch J.S. 1996. Responsiveness of Delia spp. (Diptera: Anthomyiidae) to colored sticky traps in flowering and rosette stage canola. The Canadian Entomologist 128 (06): 1077-1085.

Vernon R.S., Hunt D., Pät P., Bomford M., Collier R. 2009. Physical barriers for insect control in vegetables. IOBC/WPRS Bulletin 51: 31-37.

Walczak F. 2010. Monitoring agrofagów dla potrzeb integrowanej ochrony roślin uprawnych. Fragmenta Agronomica 27 (4): $147-154$. 